Original Research Paper

\title{
HYGLASS: Design Proposal for an Integrated Multifunctional Hybrid Glass-Steel Structure
}

\author{
Maurizio Froli and Francesco Laccone \\ Department of Energy Systems, Territory and Construction Engineering, University of Pisa, Pisa, Italy
}

Article history

Received: 02-12-2017

Revised: $15-01-2018$

Accepted: 22-01-2018

Corresponding Author:

Francesco Laccone

Department of Energy,

Systems, Territory and

Construction Engineering,

University of Pisa, Pisa, Italy

Email: francesco.laccone@destec.unipi.it

\begin{abstract}
Contemporary cities demand smart communication infrastructures to facilitate the interaction of residents and visitors with the urban environment. Such systems are required to be network-connected, interactive, environmental-sensitive and energetically self-sustaining. Moreover, in outdoor applications they should mark an urban focal point and should be able to satisfy additional public requirements like illumination, transmission of information etc. In the framework of a research program on post-tensioned glass-steel structures, the HYbrid GLAss-Steel Stele (HYGLASS) has been conceived to work, beyond its structural function, as interactive signage, digital totem or wayfinding and, gradually scaling its size, as smart landmark tower. The tetrahelical bearing structure is made of laminated glass panels, which collaborate with a filigree steel truss and embed in their interlayers miniaturized Information and Communications Technology, photovoltaic and lighting devices.
\end{abstract}

Keywords: Structural Glass, Lattice Structure, Hybridism, Post-Tensioning, Smart City, Integrated Design, Facetted Tower

\section{Introduction}

Nowadays the information exchange with the environment improves the urban experience of both residents and one-time travelers. Information and Communications Technology (ICT) is becoming fundamental in such process because the user manifests different real-time requests and cities are changing very dynamically. Consequently, a new sensitive network infrastructure is required to send, receive and manage information in a quasi-continuous stream of data.

The smart city concept takes on such opportunity and aims at creating money saving, system efficiency, adaptability by impact on public services management. Systems to act as interface with the user constitute actual needs of such novel infrastructure. Therefore, multiple and different requirements should be integrated in an aesthetically pleasing single object. Robust and reliable materials are preferable in order to avoid damages and reduce maintenance.

The HYbrid GLAss-Steel Stele (HYGLASS) project proposes a multifunctional tower to be employed for that purpose. Its modular geometry is suited for various settings according to the site requirements and its design concept allows the height size scaling from 3.00 to $30.00 \mathrm{~m}$.

A durable material like glass has been selected as main load bearing material, while a facetted triangulated tower-like geometry provides nonmimetic appeal. Due to the mechanical limitations of structural glass, essentially related to its fragility and scattered tension strength, a filigree steel truss is also combined with the transparent panels, which are additionally posttensioned by external cables.

The use of the architectural glass for structural purposes is a tendency of the last decades accommodating the desire of many designers to dematerialize the building through transparent separation surfaces and load bearing structures. The brittleness of glass differentiates it from other structural materials and requires the adoption of a special design strategy as the Fail-Safe Design (Haldimann et al., 2008) and the hybridism with ductile material (Martens et al., 2015a).

Among the hybrid solutions, glass-steel constitutes one of the most successful collaboration: Beams (Louter et al., 2012; Martens et al., 2016a; 2016b), arches (Sobek, 2007; Weller et al., 2009), domes and vaults (Weller et al., 2008; 2010; Ioannis et al., 2012) were developed.

More recently, in order to provide additional layers of redundancy and to exploit the high compressive resistance of glass, post-tensioned tendons were introduced, so crack initiation is further delayed and more robustness is achieved (Martens et al., 2015b). Hence, transparency of the surfaces is as much as possible preserved (Louter et al., 2014; Cupać et al., 
2017; Bedon and Louter, 2016; 2017; Jordão et al., 2014; Feng et al., 2015; Engelmann and Weller, 2016).

The aim of the present work is to demonstrate the feasibility of HYGLASS tower and to highlight the advantages related to its specific structural concept in terms of redundancy. The basic component elements of the structure are described and details about their modelling are reported. As case study, a $7.00 \mathrm{~m}$ tall HYGLASS is analyzed and discussed. Moreover, because of the multifunctional nature of the tower, some of the main functionalities are outlined.

\section{Structural Concept Design}

The HYGLASS originates from the Travi Vitree Tensegrity (TVT) concept, invented and patented by M. Froli to realize post-tensioned segmented glass-steel beams (Froli and Lani, 2010; Froli and Mamone, 2014) or frames spanning up to $20.00 \mathrm{~m}$ (Froli et al., 2014; 2017). Besides the three-dimensional geometrical extension of such concept, several modifications to the structural and safety philosophy are applied to make the size scalable up to $30 \mathrm{~m}$. The static concept is explained in Froli and Laccone (2018) and the main points are here briefly recalled:

- Pre-stress and segmentation are the founding principles inherited from the TVTs; both comply with the FSD and constitute a cost saving strategy, respectively reducing cracking and limiting the number of glass panels to replace in occurrence of accidental damages

- The metal truss takes on the tension stress subtracting glass panels from that task; additionally, it provides a measure of redundancy performing as an ultimate barrier before Ultimate Limit State (ULS) collapse. Therefore, in the worst-case scenario of all panels cracked the truss can support at least its own-weight and that of inert glass

- The structural components are hierarchically designed to obtain a ductile failure of the steel parts preceding the brittle cracking of glass

- Dry corner connections allow an easy assembly and substitution, avoid stress concentration and behave as a nonlinear joint transferring only compression forces from steel to glass

\section{Basic Idea and Geometry Description of the Tower}

The basic HYGLASS structural and multifunctional conception is due to the author M. Froli. The tower consists in a multitude of laminated triangular glass panels symbiotically connected to a steel truss and posttensioned by external cables.

Laminated glass panels adopt the convenient modular geometry of equilateral triangles with rounded edges and are equipped with a sacrificial outer glass layer that protects the structural cross-section and allow miniaturized hi-tech components to be integrated into the interlayer thickness. In such a way differently-equipped panels, for instance with ICT devices, Photovoltaic (PV) cells and sensors, are perfectly interchangeable and can meet several demands (Fig. 1).

The architectural design of the HYGLASS tower has been conceived to be attractive for users through its modern and evanescent appearance. Meanwhile, the use of glass material asks for an adequate structural safety design (Fig. 2).

The base geometry is the tetrahelix, a solid originated by the vertical assembly of tetrahedrons with a face-toface contact. A potentiality in such geometry was first noticed by Fuller (1982), from which the solid was named because of the occurrence of the tetrahedral module (tetra-) and the helices drawn by its edges (-helix). On its outer surface, it is possible to highlight three families of parallel cylindrical helices on the surface with different slopes with respect to the horizontal plane.

The steel truss axes are arranged to overlap the ideal tetrahelix solid edges, whereas the glass skin is shifted out of the truss with a small eccentricity enclosing the steel and assuring waterproofing to the tower. Silicone seals the glass edges. Hence, having a continuous reflectivity, the external appearance of the tower is not deeply affected by the opaque truss (Fig. 3).

Steel rods meet in six-way spatial connections. The same node is repeated at each vertex and only the ground and the top vertices differ because of the reduced connectivity. Additionally, the nodes are equipped with a device to lock, after post-tensioning, the external cables, which are arranged along the most inclined helical paths.

The steel truss is compatible with wiring since all the rods are equipped with a canalization and the nodes are optimal supports to house punctual devices.

The steel basement of the hybrid tower has a double role of solving the foundation connection and to create a service and facilities compartment. The basement is an ideal continuation of the tetrahelical geometry, but internally a steel diaphragm divides the service compartment from the inside of the transparent side. The service compartment is accessible with a small door and houses control panels, tools etc.

The ground connection is adaptable for any design according to the site requirements. A lighter and preferable fixed deep foundation can be realized by means of group of micro-piles anchored to a concrete slab. Otherwise, for limited heights of the tower, a heavier concrete slab foundation could transfer the vertical load to the soil area and balance the horizontal forces: such solution is also suitable for a portable wireless tower. Moreover, to avoid possible damages deriving from vibrations or accidental events as basement impact, exceptional wind forces or earthquakes, structural isolation can be provided at the basement level. 

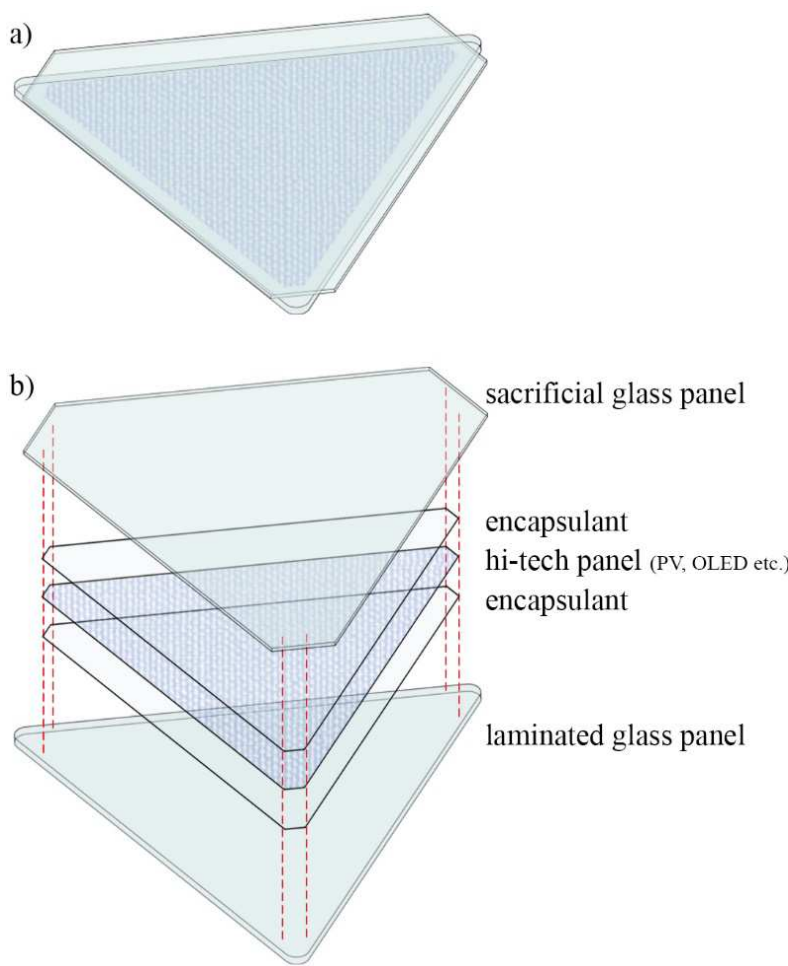

Fig. 1: Design scheme of the triangular glass panel with embedded components: (a) Overall view; (b) exploded view

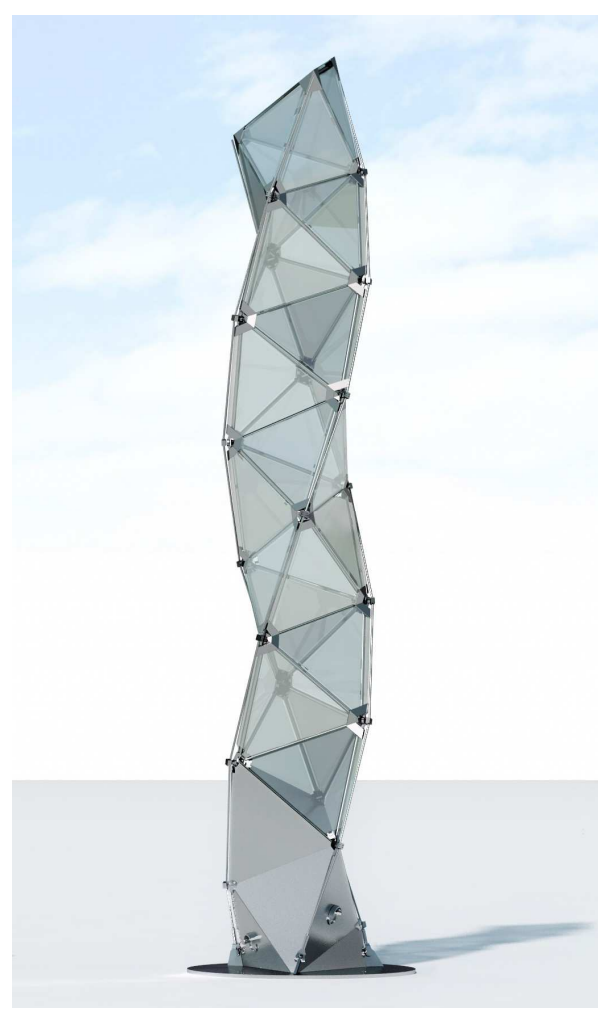

Fig. 2: Render image of a $7.00 \mathrm{~m}$ tall HYGLASS glass-steel tower

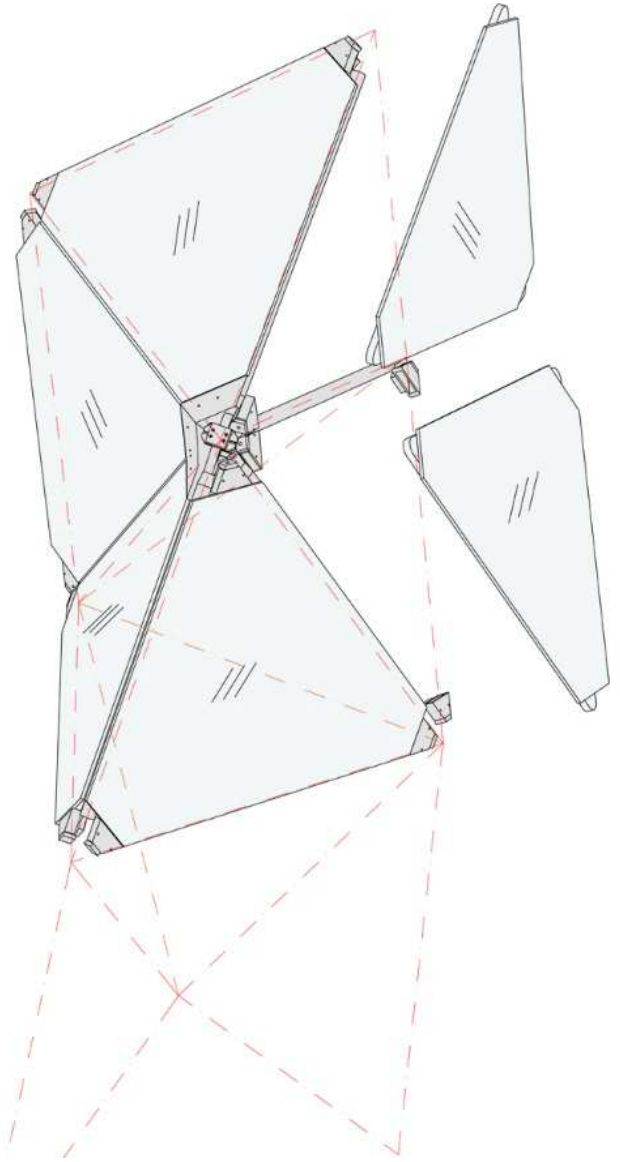

Fig. 3: Schematic assembly of the tower. The panels edges need to be successively sealed

\section{HYGLASS Multifunctionality}

In the following are presented some of uses and functions that the HYGLASS tower can perform into the urban environment. Since many of them relate to the equipment of the panels, their choice and location in the tetrahelix geometry strongly affects the appearance of the object providing design opportunities and customizations.

\section{Icon and Landmark}

Beyond the multiple tasks that the HYGLASS tower can supply, simply the glass-steel structure is usable as an iconic object and catalyst to draw attention to a specific urban area. Indeed, the facetted glass surfaces plays with the surrounding environment creating effects of superimposed transparency, reflection and refraction.

Favoured by the verticality, the Stele is able to catch the user attention as a supplementary traffic sign, for instance to indicate the presence of a round-about from a distance or to delimit a no traffic zone (Fig. 4). It could be traffic or pollution sensitive. In degraded areas the tower could also mark a site and create in its neighbourhood a place where people can meet. 


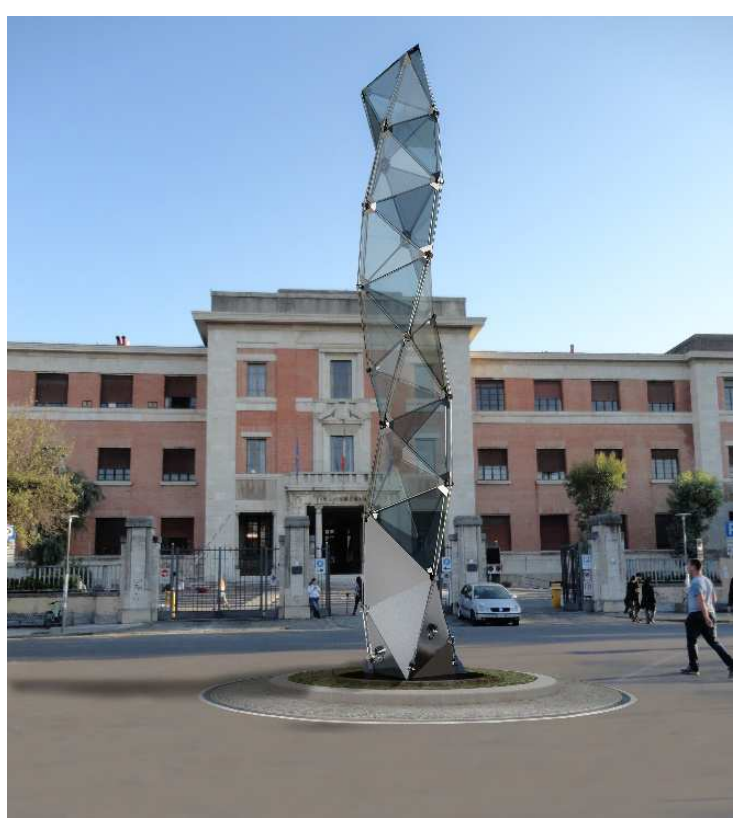

Fig. 4: Render image of a $15.00 \mathrm{~m}$ tall HYGLASS designed to be installed at a roundabout in front of the School of Engineering main building (Pisa)

If the size is scaled up to $30 \mathrm{~m}$ the tower can be positioned in public parks or naturalistic areas to allocate internally a panoramic view point to be reached through a helical staircase. Moreover, it could house and protect from weather phenomena communication systems as antennas and transmitting devices, or generally environmental sensors.

As any glass surface the panels of the HYGLASS can be equipped with coatings or printed patterns, so companies can customize them with their brands.

\section{Energy Generation, using and Storage}

Nowadays, self-sufficiency is one of the main goals of a new construction or building component. In the current case, the importance of such aspect is magnified by the energy requirement of the smart devices embedded into the HYGLASS tower.

Miniaturized embedded PV cells are commonly employed in glass roofs and facades to convert sunlight into electricity. Classic Building Integrated PV (BIPV), printed or novel transparent cells can be employed to supply the necessary energy for the tower. The electricity can be stored in lithium batteries allocated in the service compartment of tower basement, or it can be generated for the grid (Fig. 5).

Due to vertical development and the prismatic shape it is possible to install micro wind generators and store or sell the energy in the same way. In relation to the size of the tower and the amount of installed energy generators the electricity produced can be employed in numerous ways. Beyond the self-sufficiency, in public areas the tower could allow the users to plug in their devices, or a series of towers can be placed in parking areas with the aim of providing charge to electric bikes or cars.

\section{Illumination}

Signalling a spot in the twilight hours or during the night is one of function that HYGLASS can play.

Being essentially a vertical object, the tower can fulfil both as light support and as the light-emitting object itself. Moreover, light may be the mean to underline the tower or to enlighten the surrounding as public street lighting, changing the perception of the space.

Stressing the symbolic attitude of the object, assorted colours, as well as their combination and setting could identify paths and special events (Fig. 5). Light can be diffuse if provided by the panel surface or punctual if provided by lighting devices supported at the nodes.

\section{Information and Communication Technology (ICT)}

The ICT functioning is the basis of the HYGLASS project and could successfully lead its insertion in the smart city context. The tower has been indeed conceived to be sensitive and active. Multiple and variously inclined surfaces and differently-located nodal anchoring points open the way to experience a three-dimensional perception and functionality of the object.

OLEDs, displays and touch-screens are installable on the panels as digital gateway for users to access useful information or to get images and messages. The screens can show information on mobility networks and realtime mobility data.

The ICT-equipped HYGLASS could represent a WiFi access point and house antennas for diffuse Wi-Fi or mobile network, once more creating an aggregation point in the immediate proximity for citizen and visitors. To this purpose, dedicated software can also manage users' data and interact with the social media. Moreover, the tower could be integrated in the safety net of monitoring the city or a specific site, could allocate public speakers and city alarms. Digital weather monitoring is also possible by installing novel devices. Real-time data could be shown on the screens.

\section{Wayfinding}

HYGLASS landmark totems can benefit from the appeal of the shape and the flexibility of panels equipment. Small size totems can be located at city key points, at buildings entrances or floor service points, school campus, industrial or work plants, cultural heritage sites.

Such wayfinding could be static, with printed maps and signage, or digital interactive. As stated in the previous section, interactive maps can highlight paths, help users in find people's offices and services available or read descriptions. Colours, lights and design of the panels can differentiate the wayfinding or can identify a certain path or one-time event. 


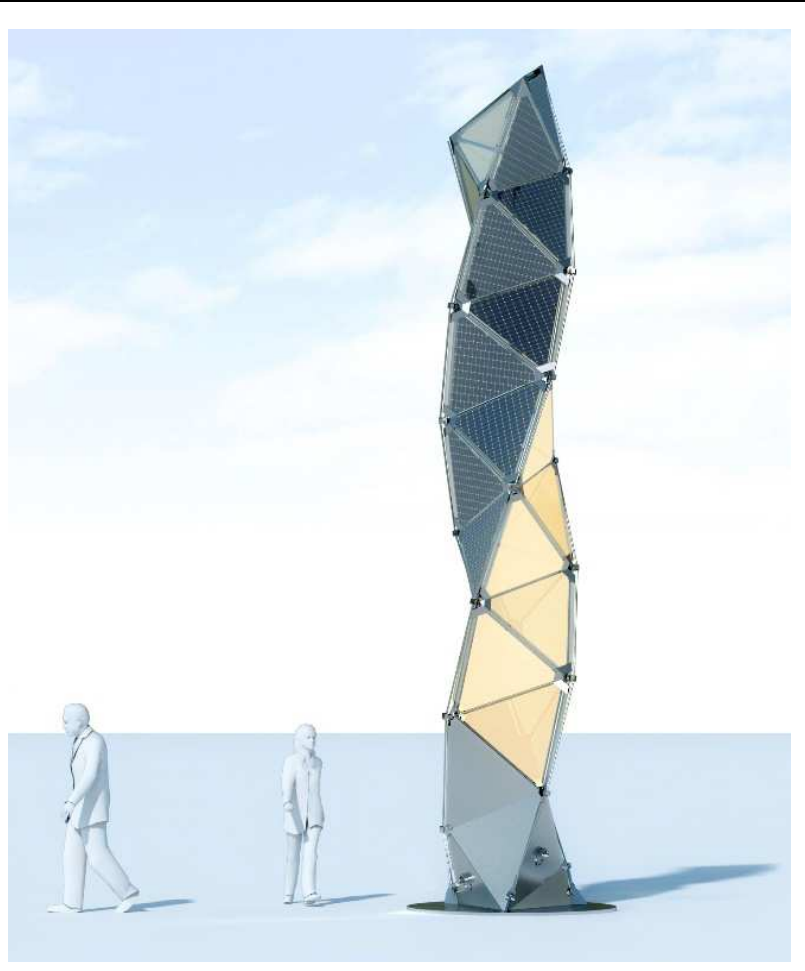

Fig. 5: Render image of a HYGLASS with embedded PV and luminescent devices

\section{Materials and Methods of the Numerical Investigations}

The design and analysis of the $7.00 \mathrm{~m}$ tall HYGLASS has been executed to assess the FSD, so state the feasibility of the structure and to measure the redundancy level. The main materials used in the model are common Heat-Strengthened Glass (HSG) and S275 steel. Aluminum spacers like those employed in the TVT $\gamma$ beam prototype has been used.

The FE model has been built and analyzed in the commercial package Straus7 release 2.3.3 (G+D Computing, 2005). Double laminated $1000 \mathrm{~mm}$ side $8+1.52+8$ HSG glass panels with PVB interlayer and hollow steel $4 \mathrm{~mm}$ thick steel tubes with $33,6 \mathrm{~mm}$ outer diameter have been selected. For the aim of this work, a less time-consuming global modelling has been conducted. Mono-dimensional and bidimensional FEs have been used to model steel components and the panels respectively. The panels are modelled as triangle panels with sharp vertex. The evaluation of glass stress peaks, which may occur because of the force transfer mechanism at the corner area, is not considered in this phase. Beam extremities have been fixed while monoliteral joints simulated the mutual connection between glass and steel. Consequently, spacers have not been introduced. The modelling phase was strongly assisted by the TVT state of the art, namely past experimental and numerical activities. Geometrical, material and contact nonlinearities have been involved. To be on the safe side, the bracing steel plates of the basement have not been included in the FE model.

Dead load has automatically been evaluated from the material characteristics, additional and sacrificial layers are introduced as a non-structural loading and wind load is applied as a face pressure on the panels.

\section{Main Results and Discussion on Feasibility}

The deformative global result of the FE analysis confirms the cantilevering behavior of the tower subject to wind prevailing loading. The maximum deflection occurs at the tip of the tower $(11.35 \mathrm{~mm}$, which yields a drift of $1.49 \cdot 10^{-3}$ ), well within the limits of the Code (1/300, NTC08).

Concerning the static behavior, regardless the scarce accuracy of the glass corner modelling, maximum principal stress on panels does not manifest significant peaks. The sudden failure is avoided because the panels remain mostly compressed due to own weight and posttensioning. The main load path on the panels is visible from the minimum principal stress shown in Fig. 6, where higher values are closer to the most inclined helices of the tetrahelix, in the closeness of the posttensioning paths.

The redundancy has been designed by graduating the steel in the worst-case scenario to achieve a global safety factor of 2.27. In this scenario, to be on the safe side the Young's modulus of glass has been set straightforwardly on $0 \mathrm{MPa}$, consequently all panels lose any mechanic relevance and only their self-weight is transferred. Outof-plane loading is distributed at the panel corners by means of load patches.

To provide an indicator $R$ (Equation 1) that measures the redundancy level, it is possible to run the ratio between the global safety factor 3.2 obtained at the ULS (wind prevailing load combination) and that one achieved in the worst-case scenario:

$R=\frac{3.2}{2.27}=1.41$

Being a hybrid structure with a global safety coefficient broadly bigger than 3.00 and having a redundancy of the $41 \%$ with respect to the improbable worst failure scenario, the design of the $7.00 \mathrm{~m}$ HYGLASS resulted well consisted.

To demonstrate the structural hierarchy of the system, the live loads acting on the structure have been successively increased. The steel yields while the panel is not failed. 


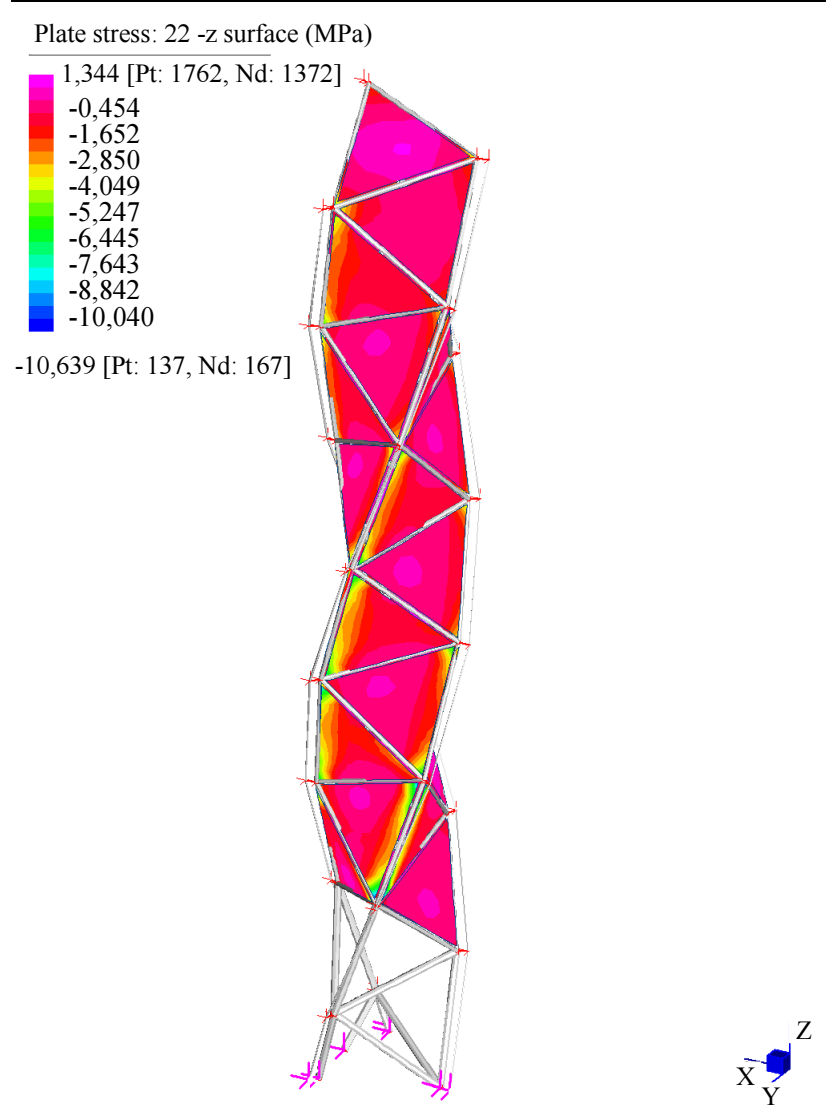

Fig. 6: FE nonlinear analysis output: Minimum principal stress on glass panels

Scalability of the structure is the key to enable the variation of size from 3.00 to $30.00 \mathrm{~m}$. The structural safety can be designed and adapted in relation to the relevance of the construction and to the loads applied. Despite the hybrid tower is already characterized by a relevant redundancy degree and a hierarchical design of the chain of failures, the steel truss could be further oversized to achieve a major residual safety coefficient in the worst-case scenario, as for instance has been done in the $7.00 \mathrm{~m}$ tower design, where the safety factor has been chosen to be 2.27 and not nearly unitary. Thus, not only the self-weight of the inert glass is supported but also part of the live loads.

Laminated panels can reach even bigger sizes up to the glass production limits. Therefore, being the panels essentially compressed, the most likely failure scenario results the buckling crisis. Limiting the slenderness is not possible by simply adopting a thicker panel because it would dramatically increase the self-weight. On the contrary, it is possible to provide additional edge out-ofplane restraint, punctual or continuous. Such expedient was successfully adopted in the design and realization of the $12.00 \mathrm{~m}$ spanned TVT $\gamma$ beam prototype. Additionally, because the restraint between steel and glass is mutual, the compression reserves of steel can be further increased.

\section{Conclusion}

The present paper proposes a smart tower-like object, named HYGLASS to be integrated into a smart city network context. Non-exhaustive list of functions and possible employments has been presented. The overall design takes on the possibility to integrate several devices to enhance the connectivity and the public role of such communicative system.

Hybridism of glass and steel is optimal strategy to realize transparent and lightweight structures marked by a sound post-breakage behaviour, well consistent with glass design philosophy. Moreover, the structural conception is adaptable with respect to the designer's risk assessment, the use of the construction and specific site quests. Based on the result of the numerical investigation, the static concept of the HYGLASS results promising concept and appears rather general, applicable to other structural geometries and tessellation and shape complexity.

The mechanical models are calibrated on the past experiences on TVTs, but further work is intended to perform experimental tests to confirm the current research study. Additionally, full resolution FE models to evaluate detailed stress fields are to be developed.

\section{Acknowledgement}

This paper was presented at the 6th International Workshop on Design in Civil and Environmental Engineering held at the University of Cagliari during November 9-10-11, 2017.

The authors would like to express gratitude to the researches that joined and are contributing in the HYGLASS project (Proff. Ceraolo, Leccese, Saletti from the University of Pisa).

\section{Author's Contributions}

Maurizio Froli: Is the conceptual designer of the structure and the research program, contributes in drafting the article and reviewing it.

Francesco Laccone: Contributes in the analysis and interpretation of results. in drafting the article and reviewing it.

\section{Ethics}

Authors should address any ethical issues that may arise after the publication of this manuscript.

\section{References}

Bedon, C. and C. Louter, 2016. Finite-element analysis of post-tensioned SG-laminated glass beams with mechanically anchored tendons. Glass Struct. Eng., 1: 39-59. DOI: 10.1007/s40940-016-0020-7 
Bedon, C. and C. Louter, 2017. Finite element analysis of post-tensioned SG-laminated glass beams with adhesively bonded steel tendons. Comp. Struct., 167: 238-250. DOI: 10.1016/j.compstruct.2017.01.086

Cupać, J., K. Martens, A. Nussbaumer, J. Belis and C. Louter, 2017. Experimental investigation of multispan post-tensioned glass beams. Glass Struct. Eng. DOI: $10.1007 / \mathrm{s} 40940-017-0038-5$

Engelmann, M. and B. Weller, 2016. Post-tensioned glass beams for a $9 \mathrm{~m}$ spannglass bridge. Struct. Eng. Int., 2: 103-113. DOI: 10.2749/101686616X14555428759000

Feng, R.Q., Y. Jihong and Y.A. Yao, 2015. New type of structure: Glass cable truss. J. Bridge Eng. DOI: 10.1061/(ASCE)BE.1943-5592.0000734

Froli, M. and L. Lani, 2010. Glass tensegrity trusses. Struct. Eng. Int., 4: 436-441. DOI: $10.2749 / 101686610793557564$

Froli, M. and V. Mamone, 2014. A $12 \mathrm{~m}$ long segmented, post-tensioned steel-glass beam (TVT Gamma). Proceedings of the Challenging Glass 4 and COST Action TU0905 Final Conference, Taylor and Francis Group, (TFG' 14), UK, pp: 243-251.

Froli, M., G. Masiello, A. Melis, V. Mamone and M. Giammattei, 2014. The energy gallery: A pilot project in Pisa. Proceedings of the International Conference at Glasstec Engineered Transparency, (GET' 14), Germany, pp: 621-628.

Froli, M., F. Laccone and D. Maesano, 2017. The TVT glass pavilion: Theoretical study on a highly transparent building made with long-spanned TVT portals braced with hybrid glass-steel panels. Build. MDPI, 7: 50-50. DOI: 10.3390/buildings7020050

Froli, M. and F. Laccone, 2018. Static concept for longspan and high-rise glass structures. J. Architectural Eng. DOI: 10.1061/(ASCE)AE.1943-5568.0000285

Fuller, R.B., 1982. Synergetics: Explorations in the Geometry of Thinking. 1st Edn., Estate of R. Buckminster Fuller, New York, ISBN-10: 0020653204, pp: 876.

$\mathrm{G}+\mathrm{D}$ Computing, 2005. Straus7 user's manual. G+D Computing: Sydney, Australia.

Haldimann, M., A. Luible and M. Overend, 2008. Structural use of Glass. 1st Edn., IABSE, Zürich, ISBN-10: 3857481196, pp: 215.

Ioannis, S.M., D. Simon, S. Nhamoinesu and M. Overend, 2012. Investigation of double-layer tensegrity glazing systems. Proceedings of the IASS Annual Symposium - IASS-APCS Seoul, (IAS' 12), South Korea.

Jordão, S., M. Pinho, J.P. Martin, A. Santiago and L.C. Neves, 2014. Behaviour of laminated glass beams reinforced with pre-stressed cables. Steel Construct., 7: 204-207. DOI: 10.1002/stco.201410027
Louter, C., J. Belis, F. Veer and J.P. Lebet, 2012. Structural response of SG-laminated reinforced glass beams; experimental investigations on the effects of glass type, reinforcement percentage and beam size. Eng. Struct., 36: 292-301. DOI: 10.1016/j.engstruct.2011.12.016

Louter, C., J. Cupać and J.P. Lebet, 2014. Exploratory experimental investigations on post-tensioned structural glass beams. J. Facade Design Eng., 2: 3-18. DOI: $10.3233 /$ FDE-130012

Martens, K., R. Caspeele and J. Belis, 2015a. Development of composite glass beams - a review. Eng. Struct., 101: 1-15. DOI: 10.1016/j.engstruct.2015.07.006

Martens, K., R. Caspeele and J. Belis, 2015b. Development of reinforced and posttensioned glass beams: Review of experimental research. J. Struct. Eng. DOI: 10.1061/(ASCE)ST.1943-541X.0001453

Martens, K., R. Caspeele and J. Belis, 2016a. Load-carrying behaviour of interrupted statically indeterminate reinforced laminated glass beams. Glass Struct. Eng., 1: 81-94. DOI: 10.1007/s40940-016-0017-2

Martens, K., R. Caspeele and J. Belis, 2016b. Numerical investigation of two-sided reinforced laminated glass beams in statically indeterminate systems. Glass Struct. Eng., 1: 417-431. DOI: 10.1007/s40940-016-0005-6

NTC08, Italian Min. Inf. Norme Tecniche per le Costruzioni.

Sobek, W., 2007. Strutture in vetro. Archi: Rivista svizzera di architettura, ingegneria e urbanistica, Swiss review of architecture. Eng. Urban Plann.

Weller, B., S. Reich, J. Ebert and P. Krampe, 2009. Testing for individual approval of a vault roof with in-plane loaded glass panes. Proceedings of the International Association for Shell and Spatial Structures Symposium (SSS’ 09), Valencia, pp: 2990-3001.

Weller, B., S. Reich and J. Ebert, 2008. Testing on space grid structures with glass as compression layer. Proceedings of the Challenging Glass Conference, (CGC' 08), Delft, pp:155-162.

Weller, B., S. Reich and J. Ebert, 2010. Transparentes Raumstabwerk über dem Innenhof des Berliner Reichstagspräsidentenpalais, Stahlbau. 79: 3-9. 